\title{
ПРАВОВОЕ ОБЕСПЕЧЕНИЕ ПОЖАРНОЙ БЕЗОПАСНОСТИ В ТОРГОВОМ ОБОРОТЕ НЕФТЕПРОДУКТОВ В РОССИИ НА РУБЕЖЕ XIX-XX ВB.
}

Б езопасность товаров относится к обязательным требованиям организации торговли. Под пожарной безопасностью товаров понимается отсутствие недопустимого риска для жизни и здоровья при хранении и эксплуатации товаров в результате возгорания или самовозгорания. На рубеже XIX-XX вв., в эпоху бурного развития частного предпринимательства и торговли, государственные власти стали обращать особое внимание на необходимость обеспечения пожарной безопасности при организации торговли минеральными маслами, нефтью и продуктами ее перегонки. С этой целью законодательно вводились специальные правила перевозки, хранения и продажи этих огнеопасных товаров.

К 1881 г. в этой сфере действовали «Правила относительно устройства складов и продажи осветительного минерального масла и петролеума, керосина, нефти и других подобных веществ» 1867 г., ${ }^{1}$ которые изначально принимались как временные (на три года), но впоследствии неоднократно продлевались.

Все склады подобной продукции делились на три категории: большие (от 150 пудов минерального осветительного материала и более, или бочками - свыше 25 шестипудовых бочек), малые (от 30 до 150 пудов или от 5 до 25 бочек) и склады розничной продажи (до 30 пудов или менее 5 бочек). Правилами определялось минимальное расстояние от складов до ближайших строений и хранилищ дров, пеньки и других легковоспламеняющихся веществ с обязательным отводом местной полицией самого места под склад (ст. 2).

В целях снижения социального пожарного риска устанавливался запрет на содержание складов рознич-

\footnotetext{
1 Полное собрание законов Российской империи. Собрание второе (ПС3 - II). Т. XLII. Отделение 1. № 44667. Июня 6 1867 г. Высочайше утвержденное положение Комитета Министров, распубликованное 10 Июля. «Об установлении временных Правил относительно устройства складов и продажи осветительного минерального масла, петролеума, керосина, нефти и других подобных веществ». С. 861; ПС3 - II. T. XLII. № 44667. Отделение 2. Высочайше утвержденные, в 6-й день июня 1867 г., по положению Комитета Министров, временные Правила относительно устройства складов и продажи осветительного минерального масла и петролеума, керосина, нефти и других подобных веществ. - С. 450-451.
}

ной продажи при лавках, расположенных на гостинных дворах и на торговых рядах. Вводились строительные нормы складских помещений, повышавшие степень их огнестойкости (ст. 6) ${ }^{2}$. Открывать склады и производить торговлю минеральным маслом, а также заниматься его очисткой дозволялось только с разрешения и после предварительного освидетельствования местной полиции (ст. 5).

Нормы техники безопасности, разработанные с учетом сложных климатических условий России и отсутствия электричества, предусматривали следующие противопожарные меры: «4. Курение табаку, разведение огня, поставка самоваров в помещении отдельных складов и для розничной продажи воспрещается. Проведение тепла дозволяется только в склады при лавках, и то, не делая топку печей из самых помещений складов, а согревая их или посредством печных стенок, или железных, или чугунных труб. Примечание. Согревание помещения нужно исключительно для обращающегося около минерального масла людей, так как оно само замерзает только при 15\% по Реомюру. ... 7. Отпуск вышеупомянутых осветительных материалов из отдельных складов и лавок, а также и переливку на месте, дозволяется производить только днем, входить во все склады со свечою, лампою и прочим освещением воспрещается, в случае же особенной надобности дозволяется входить вечером в склады при лавках, где помещается еще и другой товар, не иначе как с фонарем, окруженным железною сеткою. 8. В складах отдельных масло и нефть, во всех видах, дозволяется держать в плотно закупоренных и прочных деревянных бочках, и металлических сосудах, а в складах при лавках для розничной продажи и в самых лавках минеральное масло и прочее дозволяется держать, а также переносить из склада в лавку, только в металлических сосудах пудовой и менее вместимости, в стеклянной же и глиняной посуде не дозволяется ни держать масло в складах, ни отпускать онаго из лавки. Собственная посуда покупателей, приносимая ими за маслом, должна быть также металлическая, без течи и закупоренная. 9. Опорожненные бочки от означен-

ПС3 - II. Т. XLII. Отделение 2. К № 44667. - С. 450. 
ных веществ, по издаваемому ими зловонию, держать при лавках и складах в городе и селении не дозволяется, вывозя их немедленно. Бочек этих при больших постоянных складах не сваливать одну возле другой, а располагать на расстоянии не ближе пяти сажень. 10. Минеральное масло отнюдь не следует смешивать со скипидаром, от чего оно делается еще более летучим и воспламеняемым, дурное качество масла в этом отношении испытывать вне складов, наливая его в плоский сосуд и приближая к нему зажженную бумажку, не дотрогиваясь ею до масла, причем если масло дурно, летучее испарение от него загорается. В складах и особенно местах очищения, проливаемое масло подтирать и пол иметь без щелей» ${ }^{3}$.

Казуальный характер этих предписаний, описывавших конкретные случаи без каких-либо абстрактных формулировок и обобщений, обеспечивал их доступность для понимания обывателей. За нарушение же этих правил устанавливались меры юридической ответственности в виде штрафа: в первый раз - от десяти до двадцати пяти рублей, во второй раз - вдвое больше, в третий — в виде лишения права производить торговлю на определенный срок и др.

Но предложенные меры пожарной безопасности порой не всегда были способны существенно снизить пожарный риск: в Министерство Финансов поступали сведения о том, что на практике продаваемое масло нередко оказывалось плохого качества и это часто влекло за собой его возгорание. Тем временем в 1884 г. «Временные Правила относительно устройства складов и продажи осветительного минерального масла...» были в очередной раз продлены на пять лет (т.е. до 6 июня 1889 г.). ${ }^{4}$ А в 1886 г. по представлению Министра Финансов Н.Х. Бунге ${ }^{5}$ Высочайшее утверждение получило положение Комитета Министров, согласно которому для обеспечения качества очистки масел и определения температуры возгорания вводилось обязательное их бракование на Бакинских промыслах. Положение «Об обязательном браковании обращающихся в торговле осветительных масел» принималось как временная мера (до 6 июня 1889 г.), при этом на Министра Финансов возлагалась обязанность в течение опытного срока действия этих правил подготовить постоянные законодательные акты относительно

\footnotetext{
3 Там же. - C. 450-451.

4 ПС3 - III. T. IV. № 2300. Июня 61884 г. Высочайше утвержденное положение Комитета Министров «О сохранении действия Временных Правил относительно устройства складов и продажи осветительного минерального масла». - С. 349.

5 Министерство Финансов 1802-1902 г. Ч. ІІ. - СПб., 1902. C. 239.
}

производства и продажи осветительных минеральных масел, необходимые для обеспечения «общественной безопасности». ${ }^{6}$

Однако 8 июня 1889 г. Временные правила об обязательном браковании осветительных минеральных масел и Временные правила относительно устройства складов и продажи осветительных минеральных масел, керосина, петролеума и других подобных веществ вновь были продлены, правда всего на один год - до 6 июня 1890 г. $^{7}$

Вскоре ведомственными инструкциями были внесены изменения в порядок учреждения предприятий, связанных с производством растительных масел и их смешением с минеральными маслами. Циркуляром Хозяйственного Департамента МВД № 8853 от 31 декабря 1890 г. Список фабрик, заводов и иных промышленных заведений, «разрешение устройства коих ... выходит из пределов власти Городских общественных управлений, образованных по Городовому Положению 1870 г.» ${ }^{8}$, опубликованный при Циркуляре МВД от 28 января 1885 г. за № 740, был дополнен «включением в него заведений для приготовления смесей растительных масл как между собою, так и с минеральными маслами» ${ }^{9}$. Отныне для их открытия необходимо было особое разрешение губернского начальства. А Циркуляром № 10170 от 17 декабря 1891 г. губернаторы уведомлялись, что «при разрешении устройства фабричных и промышленных заведений в городах, где введено в действие Городовое Положение 1870 г.», дополненным списком надлежит руководствоваться в течение 1892 г. $^{10}$

6 ПС3 - III. T. VI. № 3565.Марта 81886 г. Высочайше утвержденное положение Комитета Министров «Об обязательном браковании обращающихся в торговле осветительных масл». - С. 99-100.

7 ПС3 - III. Т. IX. № 6089. Июня 81889 г. Высочайше утвержденное положение Комитета Министров «О продлении срока действия Временных Правил: а) об обязательном браковании осветительных минеральных масл, и б) относительно устройства складов и продажи осветительных минеральных масл, керосина, петролеума и других подобных веществ».- С. 330.

8 Такие списки ежегодно публиковались Министром Внутренних Дел по соглашению с Министром Финансов на основании ст. 115 Городового Положения 1870 г. и предполагали для открытия поименованных в них предприятий необходимость получения особого разрешения губернского начальства.

9 Государственный архив Оренбургской области (ГАОО). Ф. 10 (Канцелярия Оренбургского губернатора). Оп. 2. Д. 48. Л. $148-148$ об.

10 ГАОО. Ф. 10. Оп. 2. Д. 48. Л. 160. Этот список вновь был расширен Циркуляром Хозяйственного Департамента МВД за № 7 от 15.02.1894 г., обращенного губернаторам после при- 
И только 11 июня 1891 г. (т.е. с опозданием на два года от первоначально намеченного срока) правила об испытании, перевозке, хранении и продаже минеральных масел, нефти и продуктов ее перегонки были пересмотрены и дополнены ${ }^{11}$.

Высочайше утвержденным мнением Государственного Совета ${ }^{12}$, прежде всего, ужесточалась ответственность за неисполнение или ненадлежащее исполнение требований пожарной безопасности. За нарушение «предписанных законом, или изданных в установленном порядке постановлений о хранении и продаже осветительных минеральных масел» ст. $91^{1}$ Устава о наказаниях, налагаемых Мировыми Судьями, (изд. 1885 г.) вводился арест до трех месяцев или штраф до трехсот рублей. В Уложение о наказаниях уголовных и исправительных вносилось дополнение о том, что в случае совершения этого проступка в третий раз, виновные, сверх определенного наказания, подвергаются лишению навсегда права содержать склады или производить торговлю осветительными минеральными маслами. В случае же совершения подобного проступка, повлекшего за собой пожар, взрыв или причинение кому-либо смерти или вреда здоровью, виновные подвергались тюремному заключению на срок от двух до восьми месяцев ${ }^{13}$.

нятия в 1892 г. нового Городового Положения: «В виду ст. 97 Городового Положения 1892 г. (ст. 115 того же Положения 1870 г.) долгом считаю... препроводить к Вашему Превосходительству, для соответственных распоряжений, список фабрик, заводов и иных промышленных заведений, разрешение устройства коих выходит из пределов власти городских общественных управлений. При этом полагаю нелишним присовокупить, что настоящий список пополнен против опубликованного при Циркуляре Министерства Внутренних Дел от 31 декабря 1890 г. за № 8853 включением в него заведений, действующих при помощи нефтяных или керосиновых и газовых двигателей». См.: ГАОО. Ф. 10. Оп. 2. Д. 48. Л. 177. На необходимость руководствоваться им в течение 1895 г., 1896 г. и 1897 г. было указано в соответствующих Циркулярах: № 13 от 16.03.1895 г., № 12 от 13.03.1896 г. и № 1 от 19.01.1897 г. См.: ГАОО. Ф. 10. Оп. 2. Д. 48. Л. 213, 262, 288.

11 Министерство Финансов 1802-1902 г. Ч. ІІ. - СПб., 1902. C. 239 .

12 ПС3 - III. Т. ХІ. № 7812. «Высочайше утвержденные Правила об испытании, перевозке, хранении и продаже минеральных масл, нефти и продуктов ея перегонки». Мнение Государственного Совета, Высочайше утвержденное 11 июня 1891 г. - С. $381-386$

13 Эти положения соответствовали ответственности за подобные нарушения в сфере производства и торговли пороха и других взрывчатых веществ. ПСЗ - III. Т. II. № 864. «Высочайше утвержденные Временные Правила о частных складах взрывчатых веществ для надобностей горнозаводской и соляной промышленности». Мнение Государственного Совета, Высочайше утвержденное 11 Мая 1882 г., ст. 28-31. - С. 202; ПС3 - III. Т. III.
Согласно Правилам осветительные минеральные масла, сырая нефть и продукты ее перегонки по степени представляемой ими взрывоопасности подразделялись на два класса ${ }^{14}$. При этом нефть и продукты ее перегонки не могли выпускаться в продажу без предварительного их освидетельствования, а осветительные минеральные масла - до определения температуры вспышки отделяемых ими паров, осуществляемыми в соответствии со специально установленной инструкцией.

Продажа под названием керосина огнеопасных продуктов перегонки нефти запрещалась, перевозить их разрешалось только в прочной металлической или стеклянной посуде или в эмалированных деревянных бочках, скрепленных железными обручами (ст. 6). При этом закон вводил особое правило: «Посуда, в которой хранятся для продажи жидкости II класса, должна иметь на видном месте ясную и прочную надпись: «огнеопасно» ${ }^{15}$.

Определение температуры вспышки и других качеств осветительных минеральных масел, вывозимых с завода Бакинского района, возлагалось на Управление акцизными сборами Закавказского края и производилось назначаемыми Управляющим Старшими и Младшими техниками по освидетельствованию минеральных масел. Назначение техником могли получить только лица, «окончившие курс в одном из высших технических учебных заведений, или по физико-математическому факультету Университетов» ${ }^{16}$, и лишь в особых случаях, временно - другие чины Акцизного Управления, получившие специальную техническую подготовку. На нефтеперегонных заводах, расположенных вне Бакинского района эти функции возлагались на обязанность самих владельцев заводов под наблюдением чинов местного акцизного надзора. Техники обязаны были собирать статистические сведения по обработке нефти и по вывозу нефтяных продуктов из Баку, сообщая их Акцизному управлению и специ-

№ 1839. Ноября 151883 г. Высочайше утвержденное мнение Государственного Совета «О частных заведениях для приготовления капсюлей к охотничьему оружию», ст.ст. 8-11. - С. 446447. Подробнее см.: Жолобова Г.А. Особенности законодательного регулирования производства и торговли порохом и другими взрывчатыми веществами в пореформенной России 18761913 гг. // Труды Оренбургского института (филиала) МГЮА. Выпуск 14. - Оренбург, 2011. - С. 6-22.

14 К I классу относились вещества, пары которых вспыхивают при температуре не ниже $28^{\circ}$ C. (по аппарату АбеляПенскаго, при давлении воздуха в 760 мм.; ко II классу - вещества, пары которых вспыхивают при температуре ниже этой нормы (огнеопасные вещества). См.: ПС3 - III. Т. XI. № 7812, ст. 2. - С. 382 .

15 Там же, Примечание 3 к ст. 23. - С. 385.

16 Там же, ст. 13. - С. 383. 
ально учрежденному Бакинскому Техническому Комитету, а иногда и вести учет причитавшегося с осветительных нефтяных масел акциза.

Бакинский Технический Комитет, находившийся в ведении Департамента Торговли и Мануфактур Министерства Финансов, призван был разрешать на месте все недоразумения, возникавшие «при испытании минеральных масел между техниками и заводчиками или отправителями нефтяных продуктов», а также разрабатывать статистические данные по нефтеперерабатывающей промышленности ${ }^{17}$.

Правила устанавливали необходимость получения разрешения для устройства и содержания оптовых складов: в городах - по представлениям Городских Управ или заменяющих их учреждений у Губернатора или Градоначальника (по принадлежности), а вне городов - у Губернатора. Подтверждалась обязательность освидетельствования склада местной полицией «для удостоверения в правильности и безопасности его устройства» ${ }^{18}$.

Закон устанавливал следующий противопожарный режим: вводились максимальные нормы хранения веществ I и II классов для складов двух видов: средних и малых (для больших - без ограничений количества); предусматривались строительные нормы помещений для хранения этих веществ, повышавшие степень их огнестойкости и предполагавшие наличие противопожарных преград; уточнялись нормы противопожарного разрыва, т.е. их расположения по отношению к ближайшим деревянным и каменным жилым постройкам, помещениям «для паровых котлов и огнедействующих мастерских (кузниц и т.п.)» (ст. 23-26).

Розничная продажа осветительных минеральных масел и продуктов перегонки нефти могла производиться только с разрешения: в городах - Городской управы или заменяющего ее учреждения по соглашению с местной полицейской властью, а в селениях - уездного полицейского начальства. Такая продажа допускалась «как из специально предназначенных для того торговых заведений, так и из лавок свечных, москательных и мелочных, а также магазинов аптекарских товаров».

В помещениях для производства розничной продажи разрешалось хранить одновременно: а) в лавках, специально предназначенных для торговли осветительными минеральными маслами и продуктами перегонки нефти, а также в москательных лавках и лавках для продажи аптекарских товаров - не более 30 пудов веществ I класса и не свыше 10 пудов II класса; б) в свечных и мелочных лавках - исключительно осветительные

17 Там же, ст. 15, 19. - С. 383-384.

18 Там же, ст. 22. - С. 384. минеральные масла I класса в количестве не более 15 пудов. При этих торговых заведениях дозволялось устройство «отдельных каменных, крытых сводами, помещений для хранения запасов означенных веществ в количестве, не свыше 100 пудов I класса и 20 пудов II класса». Подтверждалось положение правил 1867 г. о том, что такие помещения могли «быть устраиваемы во всех частях городов и селений, за исключением гостинных дворов, торговых рядов и пассажей». При этом уточнялось, что «во дворах отдельно от торговых заведений устройство их дозволяется в расстоянии не менее 6 сажень от других построек» ${ }^{19}$.

Правилами запрещалось без особого на то разрешения акцизного надзора смешивать различные нефтяные продукты как между собою, так и с нефтью и посторонними веществами, а равно производить обработку названных масел и продуктов.

Городским и земским общественным учреждениям предоставлялось право составлять обязательные для местного населения правила о мерах, предотвращающих опасность воспламенения осветительного масла (ст. 9).

В заключении ст. 33 гласила: «Подробные правила относительно устройства помещений для хранения и продажи осветительных минеральных масел, нефти и продуктов ее перегонки, смешивания упомянутых продуктов как между собою, так и с посторонними веществами, и хранения опорожненных из под оных бочек издаются Министром Финансов, по соглашению с Министром Внутренних Дел, и представляются Правительствующему Сенату для распубликования во всеобщее сведение» ${ }^{20}$.

Наблюдение за точным исполнением Правил о перевозке, хранении и продаже осветительных минеральных масел, нефти и продуктов ее перегонки возлагалось на «местную торговую, речную и общую полиции, а также на чинов железнодорожной инспекции и управлений казенных железных дорог, по принадлежности» ${ }^{21}$.

Закон 1891 г. несомненно, явился важным звеном правового обеспечения пожарной безопасности торговли минеральными маслами, нефти и продуктов ее перегонки.

Однако на практике участились случаи недобросовестности в торговле гарными маслами. Министерство Финансов обратило внимание на то, что «фальсификация деревянного масла путем смеси растительных и специально приготовленного для этой цели минераль-

\footnotetext{
19 Там же, ст. 31. - С. 385

20 Там же. - С. 386.

21 Там же, ст. 8. - С. 383.
} 
ного масла чрезвычайно усиливалась. Между тем, такое масло непригодно для возжигания в церквах, как по религиозным основаниям, так и по его недоброкачественности и огнеопасности» ${ }^{22}$. В виду этого, по представлению Министра Финансов С.Ю. Витте торговля гарными маслами была подчинена правительственному контролю.

14 декабря 1900 г. Высочайше утвержденным мнением Государственного Совета «О мерах для предупреждения злоупотреблений в торговле гарными маслами» ${ }^{23}$ название «деревянное (лампадное) масло» было присвоено исключительно натуральному оливковому маслу, не содержащему никаких примесей. Смесям растительных масел между собой или с минеральными маслами, предназначенным для возжигания, было присвоено наименование «искусственное гарное масло». Эта надпись должна была помещаться на видных местах: на посуде, в которой хранится и отпускается гарное масло (с указанием имени или фирмы заводчика либо торговца), и на вывесках заведений, торгующих таким маслом. Виновные в несоблюдении этих правил подвергались «сверх отобрания искусственного гарного масла, денежному взысканию не свыше пятидесяти рублей» ${ }^{24}$.

Для обеспечения должной реализации этого закона на места был разослан Циркуляр Департамента Полиции Министерства Внутренних дел от 22 декабря 1901 г. № 1477 следующего содержания: «Гг. Губернаторам, Обер-Полицмейстерам и Градоначальникам. // В № 15 Собр. Узак. и Расп. Прав. за текущий 1901 г. распубликовано Высочайше утвержденное 14 декабря 1900 г. мнение Государственного Совета о мерах для предупреждения злоупотреблений в торговле гарными маслами...» Далее следовал текст закона, завершавшийся обращением к местным властям: «В виду изложенных законоположений, а также принимая во внимание, что по отзыву Министра Финансов, ближайшее наблюдение за производством искусственных гарных масл им уже поручено, в интересах соблюдения закона, чинам акцизного ведомства, имею честь покорнейше просить Ваше Превосходительство, в ограждение покупателей деревянного масла от возможных злоупотреблений и согласно ходатайству Министерства Фи-

22 Министерство Финансов 1802-1902 г. Ч. ІІ. - СПб., 1902. C. 560.

23 ПСЗ - III. Т. ХХ. № 19354. Декабря 141900 г. Высочайше утвержденное мнение Государственного Совета «О мерах для предупреждения злоупотреблений в торговле гарными маслами». С. 1101. Свод Законов Российской Империи. Т. ХІ. Ч. 2. Устав о Промышленности (Изд. 1893 г. по Прод. 1906 г.), Примечание 4 к ст. 258. - С. 1229.

24 ПСЗ - III. Т. ХХ. № 19354, ст. 11. - С. 1101. нансов, не отказать в распоряжении о том, чтобы чины вверенной Вам полиции имели неослабное наблюдение за соблюдением торговцами вышеприведенных требований закона относительно продажи искусственных гарных масл» ${ }^{25}$.

T.о. в России на рубеже XIX-XX вв. правовое обеспечение пожарной безопасности в торговом обороте нефтепродуктов осуществлялось путем: 1) установления в нормативно-правовых актах требований пожарной безопасности к такой продукции как минеральное масло, петролеум, керосин, нефть и другие подобные вещества, процессам их производства, хранения, транспортирования и реализации; 2) правового регулирования отношений в области применения и использования требований пожарной безопасности и в сфере оценки соответствия им товарной продукции. Важное место в правовом регулировании отводилось мерам юридической ответственности за нарушение установленных требований.

Правовой основой технического регулирования в области пожарной безопасности являлись специальные нормативно-правовые акты казуального характера. Установленные в них положения условно можно объединить по следующим направлениям:

1. классифицирующие пожаровзрывоопасность продукции;

2. предъявляющие особые требования к таре, в которой должна храниться нефтяная продукция;

3. закрепляющие строительные нормы для помещений, предназначенных для хранения и продажи нефтепродуктов;

4. регламентирующие правила обращения персонала с огнеопасной продукцией в процессе осуществления хранения, перевозки или торговли;

5. вводившие контроль качества продукции;

6. разрабатывающие требования к организациям и лицам, осуществлявшим оценку соответствия продукции требованиям пожарной безопасности.

Для исключения условий образования горючей среды в нормативном порядке предлагались следующие способы: 1) ограничение массы и объема горючих веществ и материалов; 2) использование наиболее безопасных способов размещения горючих веществ и материалов, взаимодействие которых друг с другом приводит к образованию горючей среды; 3) изоляция горючей среды от источников зажигания; 4) удаление из помещений пожароопасных отходов; 5) исключение условий образования в горючей среде или внесения в нее источников зажигания путем поддержания безопасной температуры нагрева веществ, материалов

25 ГАОО. Ф. 10. Оп. 1. Д. 143. Л. 198. 
и поверхностей, которые контактируют с горячей средой, и исключения условий для теплового или химического самовозгорания веществ.

Оценка соответствия продукции требованиям пожарной безопасности производилась в форме предварительного освидетельствования нефти и продуктов ее перегонки, а также определения температуры вспышки отделяемых осветительными минеральными маслами паров (их бракования). Тем же целям отвечали предварительная приемка и ввод в эксплуатацию складов для хранения огнеопасных товаров, а также осуществление последующего пожарного надзора.

Немаловажным представляется и выработка общих требований к информации о пожарной опасности веществ: формирование элементарных представлений о технической документации и информирование населения о мерах, предотвращающих опасность воспламенения минеральных масел и иной подобной продукции.

Т.о. законодательство, регламентирующее испытание, перевозку, хранение и продажу минеральных масел, нефти и продуктов ее перегонки уделяло внимание созданию системы предотвращения пожаров. Однако в таких законах отсутствовали нормы о способах и средствах пожаротушения на специализированных объектах, требования к наличию источников противопожарного водоснабжения или запасов воды, песка, и т.п. средств. Не предусматривалось устройство эвакуационных путей, применение систем индивидуальной и коллективной защиты... Т.е. задачи создания системы противопожарной защиты перед организаторами хранения и торговли минеральными маслами, нефтью и продуктами ее перегонки в анализируемых законах не ставились.

\section{Библиографический список:}

1. Государственный архив Оренбургской области (ГАОО). Ф. 10 (Канцелярия Оренбургского губернатора). Оп. 2. Д. 48.

2. ГАОО. Ф. 10. ОП. 1. Д. 143.

3. Жолобова Г.А. Особенности законодательного регулирования производства и торговли порохом и другими взрывчатыми веществами в пореформенной России 1876-1913 гг. // Труды Оренбургского института (филиала) МГЮА. Выпуск 14. - Оренбург, 2011. - С. 6-22.

4. Министерство Финансов 1802-1902 г. Ч. ІІ. СПб., 1902.

5. Полное собрание законов Российской империи. Собрание второе (ПС3 - II). T. XLII. Отделение 1. № 44667. Июня 61867 г. Высочайше утвержденное положение Комитета Министров, распубликованное 10 Июля. «Об установлении временных Правил относительно устройства складов и продажи осветительного минерального масла, петролеума, керосина, нефти и других подобных веществ». - С. 861.

6. ПС3 - II. T. XLII. Отделение 2. Высочайше утвержденные, в 6-й день июня 1867 года, по положению Комитета Министров, временные «Правила относительно устройства складов и продажи осветительного минерального масла и петролеума, керосина, нефти и других подобных веществ». С. 450-51.

7. Полное собрание законов Российской империи. Собрание третье (ПС3 - III). Т. II. № 864. «Высочайше утвержденные Временные Правила о частных складах взрывчатых веществ для надобностей горнозаводской и соляной промышленности». Мнение Государственного Совета, Высочайше утвержденное 11 Мая 1882 г. - C. 202.

8. ПСЗ - III. Т. III. № 1839. Ноября 151883 г. Высочайше утвержденное мнение Государственного Совета «О частных заведениях для приготовления капсюлей к охотничьему оружию». — С. 446-447.

9. ПСЗ - III. T. IV. № 2300. Июня 61884 г. Высочайше утвержденное положение Комитета Министров «О сохранении действия Временных Правил относительно устройства складов и продажи осветительного минерального масла». С. 349.

10. ПС3 - III. Т. VI. № 3565.Марта 81886 г. Высочайше утвержденное положение Комитета Министров «Об обязательном браковании обращающихся в торговле осветительных масл». - С. 99-100.

11. ПС3 - III. Т. IX. № 6089. Июня 81889 г. Высочайше утвержденное положение Комитета Министров «О продлении срока действия Временных Правил: а) об обязательном браковании осветительных минеральных масл, и б) относительно устройства складов и продажи осветительных минеральных масл, керосина, петролеума и других подобных веществ». - С. 330.

12. ПС3 - III. Т. ХІ. № 7812. «Высочайше утвержденные Правила об испытании, перевозке, хранении и продаже минеральных масл, нефти и продуктов ея перегонки». Мнение Государственного Совета, Высочайше утвержденное 11 июня 1891 г. - С. 381-386. 
13. ПСЗ - III. Т. ХХ. № 19354. Декабря 141900 г. Высочайше утвержденное мнение Государственного Совета «О мерах для предупреждения злоупотреблений в торговле гарными маслами». - С. 1101.

14. Свод Законов Российской Империи. Т. ХІ. Ч. 2. Устав о Промышленности (Изд. 1893 г. по Прод. 1906 г.). — C. 1229 .

\section{References (transliteration):}

1. Gosudarstvennyy arkhiv Orenburgskoy oblasti (GAOO). F. 10 (Kantselyariya Orenburgskogo gubernatora). Op. 2. D. 48.

2. GAOO. F. 10. Op. 1. D. 143.

3. Zholobova G. A. Osobennosti zakonodatel'nogo regulirovaniya proizvodstva i torgovli porokhom i drugimi vzryvchatymi veshchestvami v poreformennoy Rossii 1876-1913 gg. // Trudy Orenburgskogo instituta (filiala) MGYuA. Vypusk 14. Orenburg, 2011. - S. 6-22.

4. Ministerstvo Finansov 1802-1902 g. Ch. II. SPb., 1902.

5. Polnoe sobranie zakonov Rossiyskoy imperii. Sobranie vtoroe (PSZ - II). T. XLII. Otdelenie 1. № 44667. Iyunya 6 1867 g. Vysochayshe utverzhdennoe polozhenie Komiteta Ministrov, raspublikovannoe 10 Iyulya. «Ob ustanovlenii vremennykh Pravil otnositel'no ustroystva skladov i prodazhi osvetitel'nogo mineral'nogo masla, petroleuma, kerosina, nefti i drugikh podobnykh veshchestv». - S. 861.

6. PSZ - II. T. XLII. Otdelenie 2. Vysochayshe utverzhdennye, v 6-y den' iyunya 1867 goda, po polozheniyu Komiteta Ministrov, vremennye «Pravila otnositel'no ustroystva skladov i prodazhi osvetitel'nogo mineral'nogo masla i petroleuma, kerosina, nefti i drugikh podobnykh veshchestv». - S. 450-451.

7. Polnoe sobranie zakonov Rossiyskoy imperii. Sobranie tret'e (PSZ - III). T. II. № 864. «Vysochayshe utverzhdennye Vremennye Pravila o chastnykh skladakh vzryvchatykh veshchestv dlya nadobnostey gornozavodskoy i solyanoy promyshlennosti». Mnenie Gosudarstvennogo Soveta, Vysochayshe utverzhdennoe 11 Maya 1882 g. — S. 202.

8. PSZ - III. T. III. № 1839. Noyabrya 151883 g. Vysochayshe utverzhdennoe mnenie Gosudarstvennogo Soveta «O chastnykh zavedeniyakh dlya prigotovleniya kapsyuley k okhotnich'emu oruzhiyu». — S. 446-447.

9. PSZ - III. T. IV. № 2300. Iyunya $61884 \mathrm{~g}$. Vysochayshe utverzhdennoe polozhenie Komiteta Ministrov «O sokhranenii deystviya Vremennykh Pravil otnositel'no ustroystva skladov i prodazhi osvetitel'nogo mineral'nogo masla». - S. 349.

10. PSZ - III. T. VI. № 3565.Marta 81886 g. Vysochayshe utverzhdennoe polozhenie Komiteta Ministrov «Ob obyazatel'nom brakovanii obrashchayushchikhsya v torgovle osvetitel'nykh masl». — S. 99-100.

11. PSZ - III. T. IX. № 6089. Iyunya 81889 g. Vysochayshe utverzhdennoe polozhenie Komiteta Ministrov «O prodlenii sroka deystviya Vremennykh Pravil: a) ob obyazatel'nom brakovanii osvetitel'nykh mineral'nykh masl, i b) otnositel'no ustroystva skladov i prodazhi osvetitel'nykh mineral'nykh masl, kerosina, petroleuma i drugikh podobnykh veshchestv». - S. 330.

12. PSZ - III. T. XI. № 7812. «Vysochayshe utverzhdennye Pravila ob ispytanii, perevozke, khranenii i prodazhe mineral'nykh masl, nefti i produktov eya peregonki». Mnenie Gosudarstvennogo Soveta, Vysochayshe utverzhdennoe 11 iyunya 1891 goda. - S. 381-386.

13. PSZ - III. T. XX. № 19354. Dekabrya 141900 g. Vysochayshe utverzhdennoe mnenie Gosudarstvennogo Soveta «O merakh dlya preduprezhdeniya zloupotrebleniy v torgovle garnymi maslami». - S. 1101.

14. Svod Zakonov Rossiyskoy Imperii. T. XI. Ch. 2. Ustav o Promyshlennosti (Izd. 1893 g. po Prod. 1906 g.). — S. 1229. 